Article

\title{
Fluorinated vs. Zwitterionic-Polymer Grafted Surfaces for Adhesion Prevention of the Fungal Pathogen Candida albicans
}

\author{
Elena Masotti ${ }^{1}$, Noemi Poma ${ }^{1}$, Elisa Guazzelli ${ }^{1}$, Ilenia Fiaschi ${ }^{1}$, Antonella Glisenti ${ }^{2}$, \\ Federico Vivaldi ${ }^{1}\left(\mathbb{D}\right.$, Andrea Bonini ${ }^{1}{ }^{(0}$, Fabio Di Francesco $\left.{ }^{1}{ }^{(}\right)$, Arianna Tavanti ${ }^{3}$, \\ Giancarlo Galli ${ }^{1}\left(\mathbb{D}\right.$ ) and Elisa Martinelli ${ }^{1, *}$ \\ 1 Dipartimento di Chimica e Chimica Industriale and UdR Pisa INSTM, Università di Pisa, 56124 Pisa, Italy; \\ elenam91@gmail.com (E.M.); vio_noemia15@hotmail.com (N.P.); elisa.guazzelli@for.unipi.it (E.G.); \\ ileniafiaschi@outlook.it (I.F.); federico-vivaldi@virgilio.it (F.V.); andrea.bonini@phd.unipi.it (A.B.); \\ fabio.difrancesco@unipi.it (F.D.F.); giancarlo.galli@unipi.it (G.G.) \\ 2 Dipartimento di Scienze Chimiche, Università di Padova, 35131 Padova, Italy; antonella.glisenti@unipd.it \\ 3 Dipartimento di Biologia, Università di Pisa, 56126 Pisa, Italy; arianna.tavanti@unipi.it \\ * Correspondence: elisa.martinelli@unipi.it
}

Received: 15 January 2020; Accepted: 7 February 2020; Published: 10 February 2020

check for updates

\begin{abstract}
Fluorinated (F6) and zwitterionic, as well as phosphorylcholine (MPC) and sulfobetaine (MSA), copolymers containing a low amount (1 and $5 \mathrm{~mol} \%$ ) of 3-(trimethoxysilyl)propyl methacrylate (PTMSi) were prepared and covalently grafted to glass slides by using the trimethoxysilyl groups as anchorage points. Glass-surface functionalization and polymer-film stability upon immersion in water were proven by contact angle and angle-resolved X-ray photoelectron spectroscopy (AR-XPS) measurements. Antifouling performance of the grafted films was assayed against the yeast Candida albicans, the most common Candida species, which causes over $80 \%$ of candidiasis. Results revealed that the F6 fluorinated, hydrophobic copolymers performed much better in reducing the adhesion of C. albicans, with respect to both corresponding zwitterionic, hydrophilic MPC and MSA counterparts, and were similar to the glass negative control, which is well-known to inhibit the adhesion of $C$. albicans. A composition-dependent activity was also found, with the films of copolymer with $99 \mathrm{~mol} \%$ F6 fluorinated co-units performing best.
\end{abstract}

Keywords: Candida albicans; zwitterionic polymer; fluorinated polymer; biofouling; antifouling; adhesion

\section{Introduction}

Biofouling is generally an undesirable phenomenon that involves the organic matter deposition and/or organism colonization of surfaces upon contact with biological fluids, freshwater or seawater [1,2]. Thus, biofouling affects medical, industrial and marine fields, resulting in detriments to health and environment and increased operational costs [3-5]. In the medical field, biofilm-associated microorganisms are responsible for up to $80 \%$ of all microbial infections in humans [6,7]. Biofilms are linked to recurrent invasive infections that are difficult to eradicate because of their intrinsic resistance to antimicrobial treatments and host defense mechanisms and their excellent ability to adhere to biomaterials [8].

The increasing use of biomaterials and medical devices, such as catheters, stents, prostheses, contact lenses and implants, has led to a concomitant increase in the incidence of device-related infections, with the most common fungal infection due to Candida albicans [9,10]. Management of biofilm-associated Candida infections can be challenging due to the intrinsic drug-resistant phenotype 
of sessile fungal cells, and removal of the infected device is often required [9]. However, removal of the contaminated implant can be accompanied by complications, negatively affecting the patient's condition and the economic burden. Therefore, prevention of biofilm-associated infections currently represents a major challenge.

The surface properties, notably the surface chemical composition, of materials susceptible to fouling are known to significantly affect the biofilm formation on medical devices [11], as well as the micro- and macro-fouler colonization of ship hulls, maritime equipment and industrial implants [12-15]. One of the most promising strategies to overcome this problem is to develop anti(bio)fouling surfaces, which prevent microorganism adhesion.

The first interactions occurring among $C$. albicans cells and materials surfaces are usually hydrophobic interactions and electrostatic forces, taking place within the first $12 \mathrm{~h}$; subsequent stages involve a stronger adhesion, displayed by cell-wall glycoproteins (e.g., Als or Hwp1 proteins) [16]. This leads to formation of microcolonies (3-4 h) and biofilm aggregates organized in a bilayer composed of yeast and hyphal cells embedded in a self-produced extracellular polymeric matrix (11-30 h). C. albicans mature biofilm is then consolidated up to 38-72 $\mathrm{h}$ [17].

Among the different parameters that are reported to possibly affect Candida adhesion, including surface preconditioning with different biological fluids [12], surface roughness [8-11] and surface charge [9], one of the most relevant is surface wettability. It is widely acknowledged that C. albicans attaches more rapidly to hydrophobic, nonpolar surfaces, such as Teflon and other plastics, than to hydrophilic surfaces, such as glass and metals [18]. However, results of these studies have at times been contradictory, due to the absence of standardized methods for determining surface hydrophobicity, and the wide variability observed between different Candida species, as they may show differences in the cell-wall composition [19]. A considerable extent of variability in adhesive properties has also been described even among C. albicans isolates [20]. For instance, Kang et al. evaluated the effect of surface properties of four different types of denture-lining material (tissue conditioners, acrylic and silicone soft liners and hard reline materials) on the adhesion of $C$. albicans. Surface-energy parameters of the different materials were evaluated, and the data obtained indicated that acrylic soft liners were more hydrophilic than other materials and, together with tissue conditioners, displayed greater Candida adhesion than did silicone soft liners and hard reline materials [21].

Since hydrophobic interactions appear to play a key role in the adhesion of $C$. albicans to prosthetic materials [10], hydrophilic surface modification of biological devices has been regarded as an effective strategy to inhibit $C$. albicans colonization. Attempts have been performed to modify denture-base materials to make them more hydrophilic. In particular, Lazarin et al. coated denture-base acrylic resins with photopolymerized coatings containing zwitterionic or hydrophilic monomers and found out that those based on sulfobetaine methacrylate and 3-hydroxypropyl methacrylate significantly reduced the adhesion of $C$. albicans with respect to the untreated acrylic [22,23]. Superhydrophilic sulfobetaine-methacrylamide-based copolymers on denture surfaces were shown to enhance the hydrophilicity of the denture-base acrylic resin and reduce the initial adhesion of C. albicans [24]. Inorganic silica was also used for hydrophilic modification of acrylic denture resins, to reduce the colonization of $C$. albicans [25]. Acrylic resin surfaces were also modified by different plasma treatments, including argon, argon/oxygen and argon/sulfur hexafluoride atmospheres, in order to obtain surfaces with different wettability. Interestingly, it was found that both the hydrophobic $\mathrm{Ar} / \mathrm{SF}_{6}$ and the hydrophilic $\mathrm{Ar} / \mathrm{O}_{2}$ treated resins were able to significantly reduce the adhesion of C. albicans, regardless of the different initial contact angle values, the presence or absence of saliva and the surface roughness [26]. Silicone rubber is also used for oral cavity applications, including voice prostheses and denture soft-liners, and its surface modification with fluorinated trialkoxysilane has been proposed to enhance the resistance of silicone medical devices to C. albicans adhesion [27].

The present work aimed to better understand the effect of surface phobicity/philicity against the adhesion of the yeast pathogen C. albicans on hydrophobic, fluorinated polymers, as opposed to hydrophilic, zwitterionic polymers. In particular, we synthesized three sets of copolymers based on 
a hydrophobic fluorinated (F6) monomer, a hydrophilic zwitterionic, phosphorylcholine (MPC) or sulfobetaine (MSA), monomer with 3-(trimethoxysilyl)propyl methacrylate (PTMSi). The latter was incorporated to a minimal amount ( 1 and $5 \mathrm{~mol} \%$ ), to ensure covalent anchoring of the polymer film to a glass substrate. The copolymers were then used to produce films whose surfaces were investigated by contact angle and angle-resolved X-ray photoelectron spectroscopy measurements, both before and after immersion in water, to characterize the chemical structure of the polymer surface. Adhesion of $C$. albicans to the chemically different polymer films was assessed and related to the surface phobic/philic chemical nature. To the best of our knowledge, this is the first paper where the antifouling properties of zwitterionic and fluorinated copolymers against the yeast pathogen C. albicans are directly compared.

\section{Materials and Methods}

\subsection{Materials}

1H,1H,2H,2H-Perfluorooctyl acrylate (F6, Fluorochem, Hadfield, UK), 3-(trimethoxysilyl)propyl methacrylate (PTMSi, ABCR, Karlsruhe, Germany), $N$-(3-sulfopropyl)- $N$-(methacryloyloxyethyl)$\mathrm{N}, \mathrm{N}$-dimethylammonium betaine (MSA, Sigma Aldrich, St. Louis MO, USA), 2-methacryloyloxyethyl phosphorylcholine (MPC, Sigma Aldrich, St. Louis MO, USA), 2,2'-azobis(2-methylpropionamidine) dihydrochloride (V50, Sigma Aldrich, St. Louis MO, USA), hexafluorobenzene (HFB, Fluorochem, Hadfield, UK), $\alpha, \alpha, \alpha$-trifluorotoluene (TFT, Fluorochem, Hadfield, UK) and 2,2,2-trifluoroethanol (TFE, Sigma Aldrich, St. Louis MO, USA) were used as received. 2,2'-Azobis(isobutyronitrile) (AIBN, Sigma Aldrich, St. Louis MO, USA) was recrystallized from methanol. Toluene was kept over $\mathrm{CaH}_{2}$ for $4 \mathrm{~h}$ and then distilled. Methanol was kept over molecular sieves before use. Tetrahydrofuran (THF) was refluxed and distilled on $\mathrm{Na} / \mathrm{K}$.

\subsection{General Procedure for the Synthesis of Zwitterionic Copolymers $p$ (MSA-co-PTMSix)}

In a typical preparation, monomers MSA $(0.991 \mathrm{~g}, 3.54 \mathrm{mmol})$ and PTMSi $(10 \mu \mathrm{L}, 0.04 \mathrm{mmol})$, initiator V50 (10 mg) and anhydrous methanol $(4 \mathrm{~mL})$ were introduced into a Carius tube. The solution was outgassed by four freeze-pump-thaw cycles. The polymerization reaction was allowed to proceed under stirring at $50{ }^{\circ} \mathrm{C}$ for $6 \mathrm{~h}$. The crude product was purified by several precipitations from TFE into methanol (yield 33\%). The obtained copolymer p(MSA-co-PTMSi1) contained $99 \mathrm{~mol} \% \mathrm{MSA}$ and 1 mol\% PTMSi.

${ }^{1} \mathrm{H}$ NMR (in $\mathrm{D}_{2} \mathrm{O} / \mathrm{TFE}, \delta \mathrm{ppm}$ ): 4.60-4.40 $\left(\mathrm{COOCH}_{2}\right), 3.76-3.56\left(\mathrm{C}_{2} \mathrm{~N}^{+} \mathrm{CH}_{2}, \mathrm{OCH}_{3}\right), 3.45-3.16$ $\left(\mathrm{CH}_{2} \mathrm{~N}^{+} \underline{\mathrm{C}}_{2}, \mathrm{~N}^{+}\left(\mathrm{CH}_{3}\right)_{2}\right), 3.14-2.93\left(\mathrm{CH}_{2} \mathrm{SO}_{3}^{-}\right), 2.45-2.21\left(\mathrm{C}_{2} \mathrm{CH}_{2} \mathrm{SO}_{3}^{-}\right), 2.18-1.90\left(\mathrm{CH}_{2}\right), 1.40-0.70$ $\left(\mathrm{CH}_{3}, \mathrm{CH}_{2} \mathrm{Si}\right)$.

\subsection{General Procedure for the Synthesis of Zwitterionic Copolymers p(MPC-co-PTMSix)}

In a typical preparation, monomers MPC $(1.020 \mathrm{~g}, 3.46 \mathrm{mmol})$ and PTMSi $(8 \mu \mathrm{L}, 0.03 \mathrm{mmol})$, initiator V50 (10 mg) and anhydrous methanol $(4 \mathrm{~mL})$ were introduced into a Carius tube. The solution was outgassed by four freeze-pump-thaw cycles. The polymerization reaction was let to proceed under stirring at $50^{\circ} \mathrm{C}$ for $24 \mathrm{~h}$. The crude product was purified by several precipitations from methanol into THF (yield 85\%). The obtained copolymer p(MPC-co-PTMSi1) contained $99 \mathrm{~mol} \% \mathrm{MPC}$ and 1 mol\% PTMSi.

${ }^{1} \mathrm{H}$ NMR (in $\left.\mathrm{D}_{2} \mathrm{O}, \delta \mathrm{ppm}\right): 4.33\left(\mathrm{COOCH}_{2}, \mathrm{MPC}\right), 4.24\left(\mathrm{CH}_{2} \mathrm{O}\left(\mathrm{PO}_{2}{ }^{-}\right) \mathrm{OCH}_{2}\right), 4.12-3.90$ $\left(\mathrm{CH}_{2} \mathrm{O}\left(\mathrm{PO}_{2}^{-}\right) \mathrm{OCH}_{2}, \mathrm{COOCH}_{2} \mathrm{PTMSi}\right), 3.86-3.59\left(\mathrm{C}_{2} \mathrm{~N}^{+}\left(\mathrm{CH}_{3}\right)_{3}, \mathrm{OCH}_{3}\right), 3.27\left(\mathrm{~N}^{+}\left(\mathrm{CH}_{3}\right)_{3}\right), 2.17-1.74$ $\left(\mathrm{CH}_{2}\right), 1.19-0.66\left(\mathrm{CH}_{3}, \mathrm{CH}_{2} \mathrm{Si}\right)$.

\subsection{General Procedure for the Synthesis of Fluorinated Copolymers p(F6-co-PTMSix)}

In a typical preparation, monomers F6 $(1.27 \mathrm{~mL}$ g, $4.74 \mathrm{mmol})$ and PTMSi $(19 \mu \mathrm{L}, 0.08 \mathrm{mmol})$, initiator AIBN $(20 \mathrm{mg})$ and anhydrous toluene $(4 \mathrm{~mL})$ were introduced into a Carius tube. The solution was outgassed by four freeze-pump-thaw cycles. The polymerization reaction was let to proceed 
under stirring at $70{ }^{\circ} \mathrm{C}$ for $24 \mathrm{~h}$. The crude product was purified by several precipitations, from $\mathrm{CHCl}_{3} / \mathrm{HFB}$ into $n$-hexane (yield 60\%). The obtained copolymer p(F6-co-PTMSi1) contained $99 \mathrm{~mol} \%$ F6 and $1 \mathrm{~mol} \%$ PTMSi.

${ }^{1} \mathrm{H}$ NMR (in $\mathrm{CDCl}_{3} / \mathrm{HFB}, \delta$ ppm): $4.47\left(\mathrm{COOCH}_{2} \mathrm{~F} 6\right), 4.16-3.96\left(\mathrm{COOCH}_{2} \mathrm{PTMSi}\right), 3.63\left(\mathrm{OCH}_{3}\right)$, 2.77-2.37 $\left(\mathrm{CH}_{2} \mathrm{CF}_{2}\right), 2.10(\mathrm{CH}), 1.83\left(\mathrm{CH}_{2} \mathrm{PTMSi}, \underline{\mathrm{C}}_{2} \mathrm{CH}_{2} \mathrm{Si}\right), 1.49\left(\mathrm{CH}_{2} \mathrm{~F}_{6}\right), 1.25-1.00\left(\mathrm{CH}_{3}\right), 0.73$ $\left(\mathrm{CH}_{2} \mathrm{Si}\right)$.

${ }^{19} \mathrm{~F}-\mathrm{NMR}\left(\mathrm{CDCl}_{3} / \mathrm{CF}_{3} \mathrm{COOH}, \delta \mathrm{ppm}\right):-5\left(\mathrm{CF}_{3}\right),-38\left(\mathrm{CH}_{2} \mathrm{CF}_{2}\right)$, from -46 to $-49\left(\mathrm{CF}_{2}\right),-51\left(\mathrm{CF}_{2} \mathrm{CF}_{3}\right)$.

\subsection{Preparation of Polymer Films}

Glass microscope slides $(18 \mathrm{~mm} \times 18 \mathrm{~mm}$ ) were cleaned in hot piranha solution (concentrated sulfuric acid $/ 30 \mathrm{wt} \%$ hydrogen peroxide, $7 / 3 \mathrm{v} / \mathrm{v}$ ) for $1 \mathrm{~h}$ at $80^{\circ} \mathrm{C}$, rinsed with distilled water and kept under distilled water until use. Film deposition was carried out either by dip-coating or spin-coating.

\subsubsection{Dip-Coating}

The clean glass slides were immersed for $2 \mathrm{~h}$ in a $5 \mathrm{wt} \%$ polymer solution of $\mathrm{p}$ (MSA-co-PTMSix) in TFE, p(MPC-co-PTMSix) in methanol and p(F6-co-PTMSix) in HFB, respectively. The coated slides were heated in an oven under vacuum, at $130{ }^{\circ} \mathrm{C}$ for $14 \mathrm{~h}$, and then rinsed and sonicated for $15 \mathrm{~min}$, in water (p(MSA-co-PTMSix) and p(MPC-co-PTMSix)) or TFT (p(F6-co-PTMSix)). The coated slides were finally heated at $130^{\circ} \mathrm{C}$ for $1 \mathrm{~h}$.

\subsubsection{Spin-Coating}

Films for contact angle and XPS measurements were prepared by spin-coating. A $3 \mathrm{wt} \%$ polymer solution of $\mathrm{p}$ (MSA-co-PTMSix) in TFE, $\mathrm{p}$ (MPC-co-PTMSix) in methanol and p(F6-co-PTMSix) in HFB was spin-coated $(8500 \mathrm{rpm}, 20 \mathrm{~s})$ on one side of the activated glass slides. Slides were then heated in an oven, under vacuum, at $130^{\circ} \mathrm{C}$, overnight, and then rinsed in water ( $\mathrm{p}$ (MSA-co-PTMSix) and $\mathrm{p}\left(\right.$ MPC-co-PTMSix )) or TFT (p(F6-co-PTMSix)). The coated slides were finally heated at $130^{\circ} \mathrm{C}$ for $1 \mathrm{~h}$.

\subsection{Characterization}

${ }^{1} \mathrm{H}$ NMR and ${ }^{19} \mathrm{~F}$ NMR spectra were recorded with a Varian Gemini VRX300 spectrometer on $\mathrm{CDCl}_{3}$ and $\mathrm{CDCl}_{3} / \mathrm{CF}_{3} \mathrm{COOH}$ solutions, respectively.

Contact angles were measured by the sessile drop $(10 \mu \mathrm{L})$ method with a FTA200 Camtel goniometer, using water $\left(\theta_{\mathrm{w}}\right)$ (J. T. Baker, HPLC grade) as wetting liquid. Average $\theta_{\mathrm{w}}$ values of five measurements were reported.

X-ray photoelectron spectroscopy (XPS) spectra were recorded with a PerkinElmer PHI 5600 spectrometer with a standard Al-K $\alpha$ source $(1486.6 \mathrm{eV})$ operating at $350 \mathrm{~W}$. The working pressure was less than $10^{-8} \mathrm{~Pa}$. The spectrometer was calibrated by assuming the binding energy (BE) of the $\mathrm{Au}$ $4 \mathrm{f}_{7 / 2}$ line to be $84.0 \mathrm{eV}$, with respect to the Fermi level. Extended (survey) spectra were collected in the range $0-1350 \mathrm{eV}\left(187.85 \mathrm{eV}\right.$ pass energy, $0.4 \mathrm{eV}$ step, $\left.0.05 \mathrm{~s} \mathrm{step}^{-1}\right)$. Detailed spectra were recorded for the following regions: $\mathrm{C}(1 \mathrm{~s}), \mathrm{O}(1 \mathrm{~s}), \mathrm{Si}(2 \mathrm{p})$ and $\mathrm{F}(1 \mathrm{~s})$. The standard deviation (SD) in the BE values of the XPS line was $0.10 \mathrm{eV}$. The spectra were recorded at two photoemission angles $\phi$ (between the surface normal and the path taken by the photoelectrons) of $70^{\circ}$ and $20^{\circ}$, corresponding to sampling depths of $\sim 3 \mathrm{~nm}$ and $\sim 9 \mathrm{~nm}$ (C(1s) line), respectively. The atomic percentage, after a Shirley-type background subtraction [28], was evaluated by using the PHI sensitivity factors ( $\pm 1 \%$ experimental error) [29]. To take into account charging problems, the $\mathrm{C}(1 \mathrm{~s})$ peak was considered at $284.5 \mathrm{eV}$, and the peak BE differences were evaluated. The XPS peak-fitting procedure was carried out by means of Voigt functions, and the results were evaluated by an $\chi^{2}$ function [30].

Measurements of $\zeta$ potential were performed with a SurPass Anton Paar electrokinetic analyzer comprising a clamping cell for planar surfaces $(26 \mathrm{~cm} \times 76 \mathrm{~cm})$ parallel to each other. The measurements were conducted by forcing a $0.001 \mathrm{M} \mathrm{KCl}$ electrolyte solution through the channel via syringe pumps. The $\mathrm{pH}$ of the electrolyte was adjusted from 10.0 to 2.5 stepwise with auto $\mathrm{pH}$ titration by adding 
$0.05 \mathrm{M} \mathrm{HCl}$ and $0.05 \mathrm{M} \mathrm{NaOH}$. $\zeta$ potential was determined from streaming current data, using the Helmholtz-Smoluchowski equation [31]. An average of four measurements was used to represent each $\zeta$ potential value at any given $\mathrm{pH}$.

\subsection{Candida albicans Biofilm Formation Assay}

\subsubsection{Strain}

Candida albicans SC5314 was kindly provided by Professor Frank Odds, University of Aberdeen, UK. The reference strain SC5314 was stored in yeast peptone dextrose (YPD) broth (Difco BD, Milan, Italy) supplemented with $40 \%$ glycerol at $-20^{\circ} \mathrm{C}$ and $-80^{\circ} \mathrm{C}$, and sub-cultured on YPD agar plates at $30^{\circ} \mathrm{C}$, when necessary. C. albicans inoculum was prepared from a single colony in YPD broth and incubated at $30^{\circ} \mathrm{C}$, overnight, under agitation.

\subsubsection{Biofilm Formation Assay}

Coated glass slides were sterilized by exposure to UV light, $15 \mathrm{~min}$ by side. The concentration of each C. albicans suspension was microscopically determined, using a Bürker's chamber and adjusted $2 \times$ $10^{7}$ cells mL ${ }^{-1}$ in RPMI 1640 medium (supplemented with $2 \%$ glucose and morpholinepropanesulfonic acid (MOPS), pH 7) (Sigma Aldrich, St. Louis MO, USA). Slides were immersed in a $50 \mathrm{~mL}$ glass tube containing $7 \mathrm{~mL}$ of yeast suspension already prepared at the desired concentration in RPMI medium.

Cells were allowed to adhere to the polymer surface for $90 \mathrm{~min}$ at $37^{\circ} \mathrm{C}$, under agitation. Following incubation, non-adhered cells were removed by washing twice in phosphate-buffered saline (PBS) $1 \times$. Then, $7.5 \mathrm{~mL}$ of RPMI 1640 medium (supplemented with $2 \%$ glucose and MOPS, pH 7) was added, and the glass cover slides were incubated at $37^{\circ} \mathrm{C}$ for $24 \mathrm{~h}$, in static conditions, to allow biofilm formation. Planktonic cells were removed by washing twice with PBS $1 \times$. The slides were then transferred into a sterile 6 flat-bottomed-well microtiter plate, and $2 \mathrm{~mL}$ of PBS $1 \times$ was added to each well; biofilm-embedded cells were detached from the slide surface with a cell scraper. A replica set of each slide was used for microscopic analysis. The morphology of sessile cells was visualized under an inverted microscope (Olympus IMT-2) at 400× magnification.

Cells were transferred in a $2 \mathrm{~mL}$ tube, and cell aggregates were dissolved by sonication for $5 \mathrm{~min}$ and vortex for other $5 \mathrm{~min}$. Cell dilutions were then prepared in PBS $1 \times$, and then $200 \mu \mathrm{L}$ was plated on a YPD agar plate and incubated at $30^{\circ} \mathrm{C}$ overnight. Finally, individual colonies were counted, and results were expressed as colony-forming units (CFU) per slide.

All aforementioned polymer films were evaluated as substrates for fungal biofilm formation, a glass slide of the same area was included as a negative control. Three independent experiments were performed, each in triplicate. Results were expressed as means \pm standard deviation. Statistical analysis was performed by using the Kruskal-Wallis test, followed by Dunn's test, with a significance level of $p \leq 0.05$.

\section{Results and Discussion}

\subsection{Synthesis of Copolymers}

Zwitterionic copolymers p(MSA-co-PTMSix) and p(MPC-co-PTMSix) based on hydrophilic MSA and MPC were synthesized by free-radical polymerization at $50{ }^{\circ} \mathrm{C}$, by using anhydrous methanol as solvent (10 $\mathrm{mL} \mathrm{g}^{-1}$ monomers) and V50 (1 wt\%) as initiator (Figures 1 and 2). V50 was chosen in place of more common thermal initiators, such as AIBN, owing to its higher solubility in methanol and its lower activation temperature $\left(t_{1 / 2}=13 \mathrm{~h}\right.$ at $50{ }^{\circ} \mathrm{C}$ [32]). Fluorinated copolymers p(F6-co-PTMSix) based on hydrophobic (and lipophobic) F6 counterpart were synthesized in anhydrous toluene solution at 70 ${ }^{\circ} \mathrm{C}$, by using $\operatorname{AIBN}(1 \mathrm{wt} \%$ ) as free-radical initiator (Figure 3). 


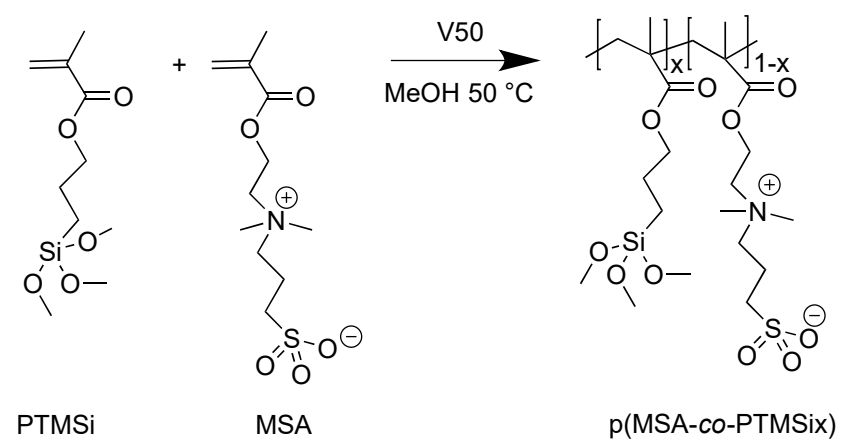

Figure 1. Synthesis of the zwitterionic copolymers based on hydrophilic MSA and PTMSi $(x=1,5$ $\mathrm{mol} \%)$.

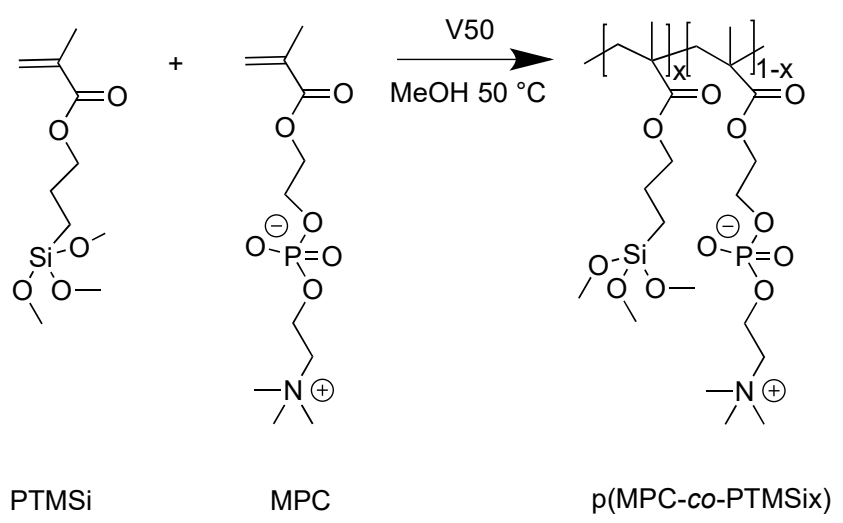

Figure 2. Synthesis of the zwitterionic copolymers based on hydrophilic MPC and PTMSi $(x=1,5$ $\mathrm{mol} \%$ ).

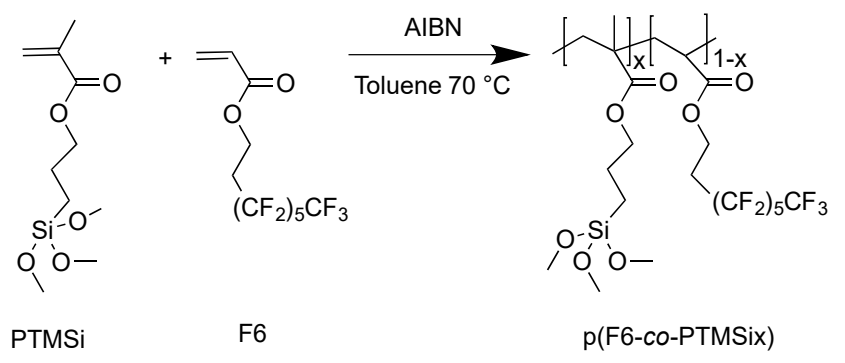

Figure 3. Synthesis of the fluorinated copolymers based on hydrophobic F6 and PTMSi $(\mathrm{x}=1,5 \mathrm{~mol} \%)$.

For any set of copolymers, an intentionally low amount of PTMSi counits ( $x=1$ and 5 mol\%) was incorporated in the copolymer to warrant covalent anchorage of the copolymer to the glass surfaces through a "grafting-to" reaction during the polymer film preparation. The MPC-based copolymers were soluble in methanol, ethanol and water and poorly soluble in less polar solvents, such as THF and acetone. Therefore, they were purified by repeated precipitations from methanol solutions into THF. Differently, MSA-based copolymers were insoluble in ethanol, methanol and water and thus were purified by repeated precipitations from the very polar TFE) into methanol. The poor solubility of the MSA-based copolymers in water at room temperature was consistent with the known UCST behavior of the corresponding $\mathrm{p}$ (MSA) homopolymer. The fluorinated copolymers were purified by repeated precipitations from HFB solutions into hexane.

The actual formation of copolymers was confirmed by ${ }^{1} \mathrm{H}$ NMR and ${ }^{19} \mathrm{~F}$ NMR (p(F6-co-PTMSix)). The composition was calculated from the integral intensities of the signals of PTMSi at $3.6 \mathrm{ppm}\left(\mathrm{OCH}_{3}\right)$ or $0.7 \mathrm{ppm}\left(\mathrm{SiCH}_{2}\right)$ and the typical signals of the corresponding comonomers $\left(4.47 \mathrm{ppm}\left(\mathrm{COOCH}_{2}\right.\right.$, F6), $\left.3.27 \mathrm{ppm}\left(\mathrm{N}^{+}\left(\mathrm{CH}_{3}\right)_{3}\right), \mathrm{MPC}\right)$ and $\left.2.35\left(\mathrm{CH}_{2} \mathrm{CH}_{2} \mathrm{SO}_{3}{ }^{-}, \mathrm{MSA}\right)\right)$. The copolymerization runs were 
carried out up to almost complete conversion of monomers (95\%-99\%), which made the subsequent work-up steps much easier. The monomer conversion $p$ was followed by ${ }^{1} \mathrm{H}$ NMR spectroscopy (see Figure 4 for one illustration example) and calculated according to Equation (1):

$$
p=1-I_{(6.05 \mathrm{t}=\mathrm{x})} / I_{(6.05 \mathrm{t}=0)}
$$

where $I_{(6.05 \mathrm{t}=x)}$ and $I_{(6.05 \mathrm{t}=0)}$ are the integrals of the signals of vinyl proton at $6.05 \mathrm{ppm}$ at different reaction times and at the initial time, respectively. At such high final comonomer conversions, the copolymer composition was equal to that of the respective monomer feed.

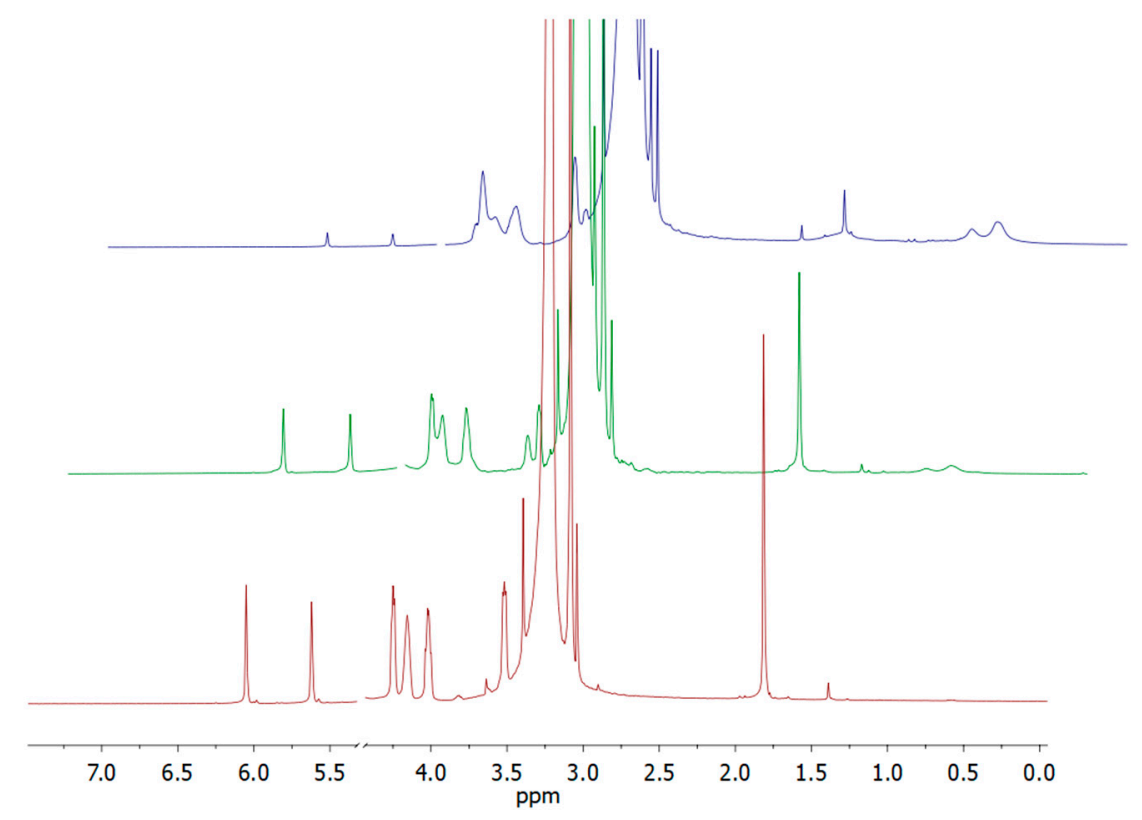

Figure 4. ${ }^{1} \mathrm{H}$ NMR spectra recorded at different reaction times ( $t=0,4$ and $24 \mathrm{~h}$ from bottom to top) during the synthesis of copolymer $\mathrm{p}$ (MPC-co-PTMSi1).

At the end of the polymerization, a suitable solvent (TFE, methanol and TFT for p(MSA-co-PTMSix), $\mathrm{p}$ (MPC-co-PTMSix) and p(F6-co-PTMSix), respectively) was added to dilute the copolymer solutions that were then stored under nitrogen at $-20^{\circ} \mathrm{C}$. The molar masses and molar mass distributions of the copolymers could not be determined, owing to their poor solubility in the common solvents normally used for GPC analyses. Moreover, it was observed that the copolymers were difficult to handle because of the hydrolysis and sol-gel condensation of the $\mathrm{Si}\left(\mathrm{OCH}_{3}\right)_{3}$ groups of PTMSi counits.

\subsection{Preparation of Polymer Films}

Polymer films of the three different classes of copolymers were prepared via a "grafting-to" approach to covalently anchor the films to the glass surface, in order to prevent their delamination during biological assays, especially of those containing hydrophilic zwitterionic MSA and MPC. Before functionalization, glass slides were activated by immersion in hot piranha solution, thus cleaning the glass surface and forming additional silanol $(\mathrm{Si}-\mathrm{OH})$ groups at the outermost surface layers $(\sim 20 \AA)$. The formation of such $\mathrm{Si}-\mathrm{OH}$ groups was also inferred by the decreased water contact angle from $28 \pm 1^{\circ}$ to $20 \pm 3^{\circ}$ in going from the non-activated to the activated glass. After cleaning, the glass slides were stored in deionized water. The $\mathrm{Si}-\mathrm{OH}$ groups were then exploited as anchorage points to bind the polymer films through a condensation sol-gel reaction with the silanol functionalities derived from the hydrolysis of the pendant PTMSi trimethoxysilyl groups promoted by ambient humidity (Figure 5). A $5 \mathrm{wt} \%$ copolymer solution was deposited by dip-coating on activated glass slides and thermally annealed at $130{ }^{\circ} \mathrm{C}$ in an oven, under vacuum, in order to remove the solvent and drive the 
cure reaction to completeness. The solvent of choice varied on the basis of the copolymer, being TFE, methanol and HFB for p(MSA-co-PTMSix), p(MPC-co-PTMSix) and p(F6-co-PTMSix), respectively. The polymer films were then copiously rinsed with and sonicated in water and TFT for zwitterionic and fluorinated copolymers, respectively, to remove the physically adsorbed polymer and residual traces of unreacted monomers. Films were finally annealed at $130^{\circ} \mathrm{C}$ for $1 \mathrm{~h}$.

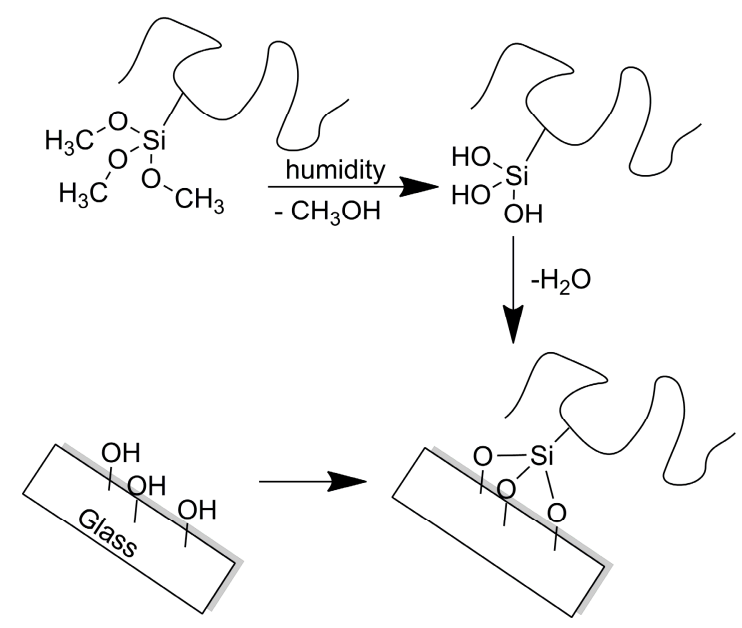

Figure 5. Schematic of the chemical functionalization of the glass slides with the zwitterionic and fluorinated copolymers containing PTMSi counits through a "grafting-to" approach.

\subsection{Water Contact Angle and Surface Chemistry}

Static contact angles with water $\left(\theta_{\mathrm{w}}\right)$ were measured on polymer films covalently grafted to the glass slide and compared with those of the bare glass and the respective homopolymers. Data are collected in Table 1 . Copolymers $\mathrm{p}$ (F6-co-PTMSix) showed values of $\theta_{\mathrm{w}}$ higher than $90^{\circ}$ similar to that of the respective homopolymer $\mathrm{p}(\mathrm{F} 6)$ and consistent with the hydrophobic nature of fluorinated (co)polymers [33-35]. On the other hand, both MSA and MPC copolymers displayed lower $\theta$, even though significantly higher than those of the corresponding homopolymers $\mathrm{p}$ (MSA) and $\mathrm{p}(\mathrm{MPC})$. This result was unexpected on account of the high content of zwitterionic counits $(95 \mathrm{~mol} \%)$ in $\mathrm{p}$ (MPC-co-PTMSi5) and p(MSA-co-PTMSi5). A moderate hydrophilic nature was previously observed for poly(MPC-co-n-butyl methacrylate) and poly(MPC-co-2-methacryloyloxy-4-azidobenzoate) films with $\theta_{\mathrm{w}}$ values of approximately $60^{\circ}$ and $50^{\circ}$, respectively [36]. However, most of the studies in literature showed that zwitterionic copolymers are markedly hydrophilic materials $\left(\theta_{\mathrm{w}}=15^{\circ}-30^{\circ}\right)$ [37]. The comparatively high hydrophobicity of the zwitterionic copolymers of this work is possibly due to the surface segregation of low surface energy siloxane groups derived from the condensation between trialkoxysilyl moieties during the covalent grafting to the glass substrate.

Table 1. Water contact angle for fluorinated and zwitterionic copolymers, the corresponding homopolymers and activated glass.

\begin{tabular}{cc}
\hline Film & $\boldsymbol{\theta}_{\mathbf{w}}\left(^{\circ}\right)$ \\
\hline $\mathrm{p}$ (F6-co-PTMSi5) & $115 \pm 2$ \\
$\mathrm{p}$ (F6-co-PTMSi1) & $116 \pm 3$ \\
$\mathrm{p}($ MSA-co-PTMSi5) & $66 \pm 5$ \\
$\mathrm{p}($ MPC-co-PTMSi5) & $69 \pm 2$ \\
$\mathrm{p}$ (F6) & $111 \pm 1$ \\
$\mathrm{p}($ MSA $)$ & $10 \pm 5$ \\
$\mathrm{p}($ MPC $)$ & $10 \pm 5$ \\
Glass & $20 \pm 3$ \\
\hline
\end{tabular}


To gain a better comprehension of the film surface composition on account of the findings from biological assays with C. albicans (see below, Section 3.4), angle-resolved X-ray photoelectron spectroscopy (AR-XPS) measurements were performed at photoemission angles $\phi$ of $70^{\circ}$ and $20^{\circ}$ on the films, before and after water immersion for $24 \mathrm{~h}$ on the films of copolymers $\mathrm{p}$ (MPC-co-PTMSi5) (Figure 6) and p(F6-co-PTMSix) (Figure 7). The former was also taken as illustration examples of the zwitterionic polymer films for determination of their surface charge by $\zeta$ potential measurements at different $\mathrm{pH}$ values.

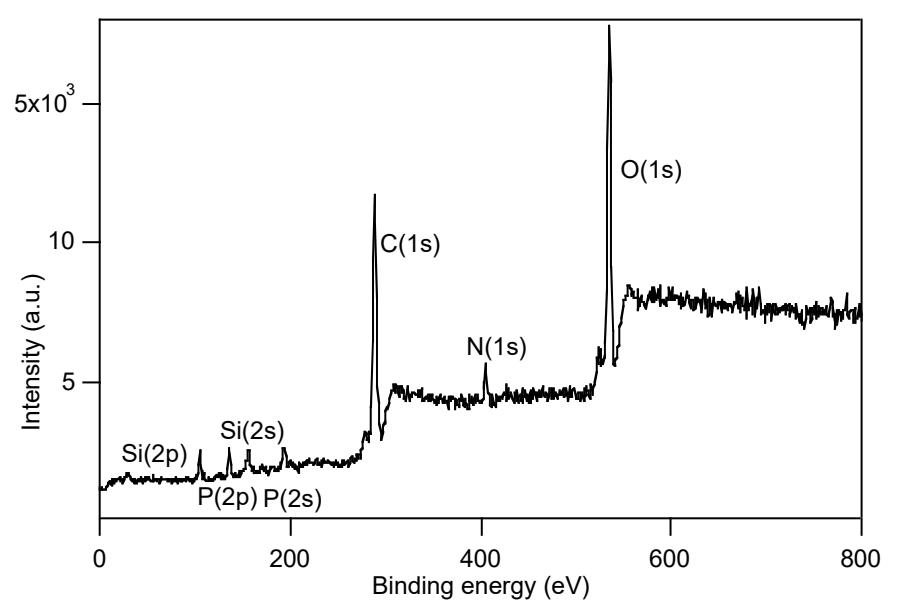

Figure 6. XPS survey spectrum for $\mathrm{p}(\mathrm{MPC}-\mathrm{co}-\mathrm{PTMSi5})\left(\phi=70^{\circ}\right)$.

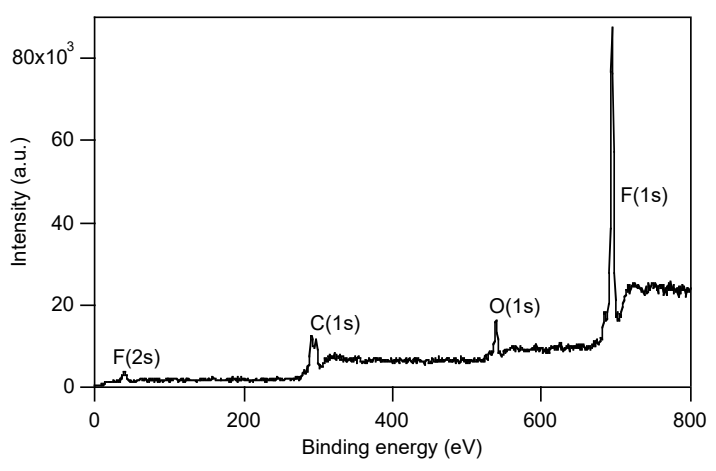

(a)

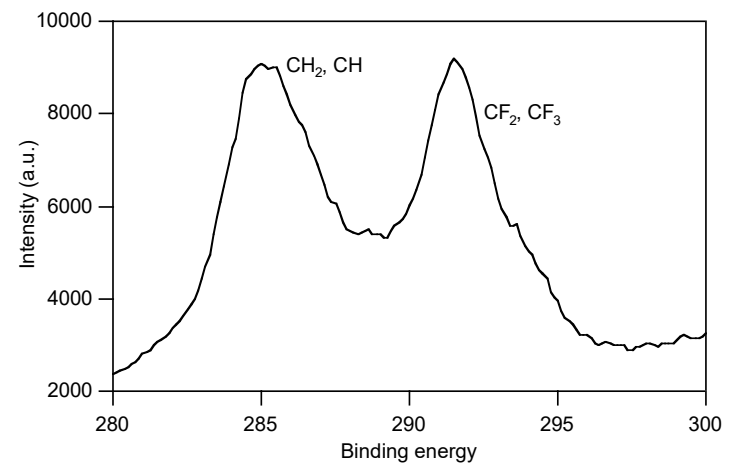

(b)

Figure 7. XPS survey (a) and high-resolution (b) spectra for $\mathrm{p}(\mathrm{F} 6-\mathrm{co}-\mathrm{PTMSi} 5)\left(\phi=70^{\circ}\right)$ after immersion in water for $24 \mathrm{~h}$.

Quantitative XPS data are reported in Table 2. In p(MPC-co-PTMSi5) film, the presence of P (P(2p) and $\mathrm{P}(2 \mathrm{~s}))$ and $\mathrm{N}(\mathrm{N}(1 \mathrm{~s}))$ moieties at the surface suggests that the glass slides were effectively covalently functionalized with the copolymer (Figure 6). Their atomic percentages were slightly lower than the theoretical ones and did not change significantly by varying the photoemission angle, indicating that the concentration of the phosphorylcholine side chain was essentially constant along the investigated sampling depth. On the other hand, $\operatorname{Si}(\operatorname{Si}(2 p)$ and $\operatorname{Si}(2 s))$ was detected with a content that, although relatively low in absolute value, was significantly higher than the theoretical one and decreased by increasing the sampling depth. These results indicate that siloxane groups were concentrated at the outermost surface layers, being the lowest surface energy components in the copolymer system. These findings are consistent with the contact angle analysis and suggest the hypothesis of siloxane bond formation as a result of the condensation of methoxysilyl/silanol groups of PTMSi. Upon immersion in water for up to one week, the surface of p(MPC-co-PTMSi5) film still presented Si moieties at the surface and overall the chemical composition after one week of immersion did not differ significantly from that before immersion. This is in contrast to what is normally expected of amphiphilic surfaces in which 
reconstruction of the outer surface occurs to respond to the changed aqueous outer environment [38]. We speculate that the interchain siloxane groups once formed were stable and did not rearrange upon contact with water.

Table 2. AR-XPS atomic surface percentages of $\mathrm{p}$ (MPC-co-PTMSi5) and p(F6-co-PTMSix) before and after immersion in water.

\begin{tabular}{|c|c|c|c|c|c|c|c|c|}
\hline Film & & $\begin{array}{c}\phi \\
\left({ }^{\circ}\right)\end{array}$ & $\begin{array}{c}\mathrm{N} \\
(\%)\end{array}$ & $\begin{array}{c}P \\
(\%)\end{array}$ & $\begin{array}{c}\mathrm{C} \\
(\%)\end{array}$ & $\begin{array}{c}O \\
(\%)\end{array}$ & $\begin{array}{c}\mathrm{Si} \\
\mathbf{( \% )}\end{array}$ & $\begin{array}{c}F \\
(\%)\end{array}$ \\
\hline \multirow{7}{*}{ p(MPC-co-PTMSi5) } & before & 70 & 2.8 & 3.2 & 59.8 & 29.5 & 4.7 & - \\
\hline & & 20 & 3.9 & 3.4 & 59.5 & 31.1 & 2.1 & - \\
\hline & & theor. ${ }^{1}$ & 5.0 & 5.0 & 58.1 & 31.6 & 0.3 & \\
\hline & after & $70^{2}$ & 2.8 & 1.8 & 67.1 & 23.9 & 4.4 & - \\
\hline & & $20^{2}$ & 4.5 & 2.6 & 61.0 & 29.4 & 2.5 & - \\
\hline & & $70^{3}$ & 1.1 & 1.2 & 60.0 & 26.9 & 10.7 & - \\
\hline & & $20^{3}$ & 3.8 & 2.6 & 59.4 & 30.4 & 3.9 & - \\
\hline \multirow{5}{*}{ p(F6-co-PTMSi5) } & before & 70 & - & - & 37.2 & 6.0 & 0.2 & 56.6 \\
\hline & & 20 & - & - & 41.9 & 7.3 & 0.2 & 50.6 \\
\hline & & theor. $^{1}$ & & & 43.0 & 8.4 & 0.2 & 48.4 \\
\hline & after & $70^{3}$ & - & - & 40.1 & 7.8 & 1.2 & 50.9 \\
\hline & & $20^{3}$ & - & - & 44.0 & 8.9 & 0.7 & 46.4 \\
\hline \multirow{5}{*}{$\mathrm{p}(\mathrm{F} 6-\mathrm{co}-\mathrm{PTMSi1})$} & before & 70 & - & - & 38.2 & 5.8 & 0 & 56.0 \\
\hline & & 20 & - & - & 41.9 & 6.7 & 0 & 51.4 \\
\hline & & theor. $^{1}$ & & & 42.4 & 7.8 & $<0.1$ & 49.7 \\
\hline & after & $70^{3}$ & - & - & 39.7 & 6.6 & 1.1 & 52.6 \\
\hline & & $20^{3}$ & - & - & 44.2 & 8.9 & 0.8 & 46.1 \\
\hline
\end{tabular}

${ }^{1}$ Theoretical percentage evaluated on the basis of the stoichiometric composition of the copolymer. ${ }^{2}$ After immersion for one week. ${ }^{3}$ After immersion for $24 \mathrm{~h}$.

AR-XPS analysis of p(F6-co-PTMSix) films revealed that their surfaces were highly enriched in F $(\mathrm{F}(1 \mathrm{~s}))$ moieties, with a percentage similar for both $\mathrm{p}$ (F6-co-PTMSi1) and $\mathrm{p}$ (F6-co-PTMSi5) and higher than the theoretical one, especially at $\phi=70^{\circ}$ (Table 2). Moreover, the F percentage decreased with increasing the sampling depth, while $\mathrm{C}$ and $\mathrm{O}$ percentages followed the opposite trend. Thus, the fluorinated chains were selectively located at the outermost surface layers. For these samples, the amount of Si at the surface was very low, consistent with the theoretical amount in the copolymer. Accordingly, the siloxane groups were segregated in the bulk of the film. Similar remarks are also valid for the films after immersion in water, which presented a slightly increase in $\mathrm{Si}$ and a decrease in F concentrations. The F moieties, however, remained the predominant components (Figure 7a). The presence of the resolved peak at $\sim 292 \mathrm{eV}$ in the $\mathrm{C}(1 \mathrm{~s})$ spectrum (Figure $7 \mathrm{~b}$ ) due to the $\mathrm{CF}_{2}$ and $\mathrm{CF}_{3}$ groups of $\mathrm{F} 6$ confirmed that the fluorinated side chains populated the film surface after immersion in water. As a result, no variation in water contact angle after $24 \mathrm{~h}$ of immersion was detected $\left(\theta_{\mathrm{w}}=115^{\circ}\right.$ \pm 2 and $\theta_{\mathrm{w}}=116^{\circ} \pm 1$ for $\mathrm{p}$ (F6-co-PTMSi5) and $\mathrm{p}$ (F6-co-PTMSi1), respectively).

The values of electrokinetic $\zeta$ potential of coated glass slides with copolymer p(MPC-co-PTMSi5) exhibited an ascending trend with decreasing $\mathrm{pH}$ and comprised a broad negative plateau $(-55 \pm$ $5 \mathrm{mV}, \mathrm{pH}>6.5)$, an isoelectric point $(\mathrm{pH}=3.7)$ and a narrow positive plateau $(\sim 20 \pm 1 \mathrm{mV}, \mathrm{pH}<$ 3 ). Bare glass slides were negatively charged over the whole $\mathrm{pH}$ investigated range (plateau value of $-75 \pm 2 \mathrm{mV}, \mathrm{pH}>4.5$ ) and an isoelectric point at $\mathrm{pH}=2.6$. Thus, functionalization of the glass surface by MPC was further confirmed, including accumulation of phosphate anion groups at the polymer-water interface. Such values of plateau of $\zeta$ potential are consistent with those reported for different phosphorylcholine-modified [39,40] and sulfobetaine-modified [41,42] surfaces. The coated surfaces appeared not to readjust under the adopted experimental conditions, as inferred by the reproducibility on repeated measurements, nor was detachment of polymer film from the glass surface 
observed in any case. These findings could ensure stability of the tested films during the subsequent biological assays.

\subsection{Biological Assays with C. albicans}

Results on the ability of $C$. albicans to adhere to, and form biofilm on, the films of zwitterionic and fluorinated copolymers are summarized in Figure 8, which shows the numbers of sessile cells adhered ( $\mathrm{CFU} \mathrm{cm}{ }^{-2}$, surface area $\left.1.8 \mathrm{~cm} \times 1.8 \mathrm{~cm}\right)$ to each slide, following incubation for $24 \mathrm{~h}$ to a cell concentration of approximately $2 \times 10^{7}$ cells mL $\mathrm{mL}^{-1}$ for $24 \mathrm{~h}$. Glass surface was also tested as a negative standard, which is known to inhibit the adhesion of $C$. albicans. The results demonstrate a marked reduction in C. albicans adhesion on fluorinated surfaces with respect to zwitterionic ones, with the fluorinated p(F6-co-PTMSi1) copolymer, showing comparable antifouling performance to that of the negative standard. Inverted microscope analyses of different surfaces revealed the presence of the filamentous forms associated with biofilm formation, with a higher prevalence of hyphal forms on zwitterionic polymers (Figure 9).

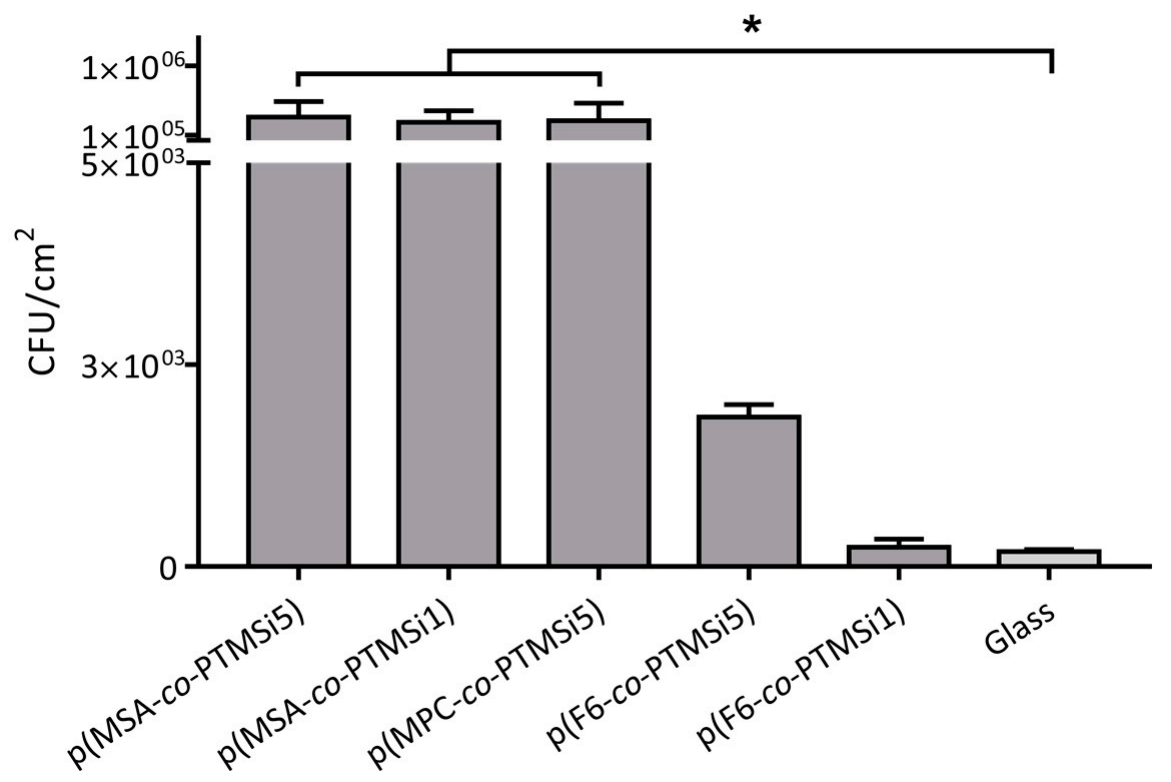

Figure 8. Adhesion of $C$. albicans to zwitterionic and fluorinated films; ${ }^{*} p \leq 0.05$ (first set of experiments).

Since the high variability observed between zwitterionic and fluorinated polymers prevented to assess potential differences in fungal adhesion on fluorinated surfaces with different chemical composition, a second set of experiments of colonization on p(F6-co-PTMSix) films was performed to

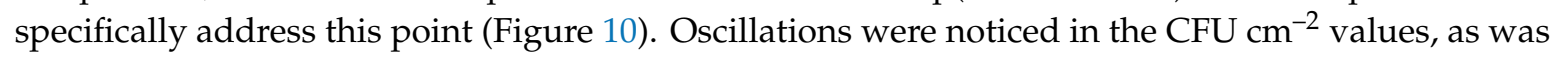
expected of the variability of adhesion tests carried out with $C$. albicans at different times. The results confirmed that adhesion of cells on p(F6-co-PTMSi1) was significantly lower than on p(F6-co-PTMSi5) $\left(1.0 \times 10^{3} \mathrm{CFU} \mathrm{cm}{ }^{-2}\right.$ vs. $\left.2.3 \times 10^{4} \mathrm{CFU} \mathrm{cm}^{-2}\right)$, and consistently a higher number of fluorinated units in the copolymer better reduced the adhesion of Candida. 

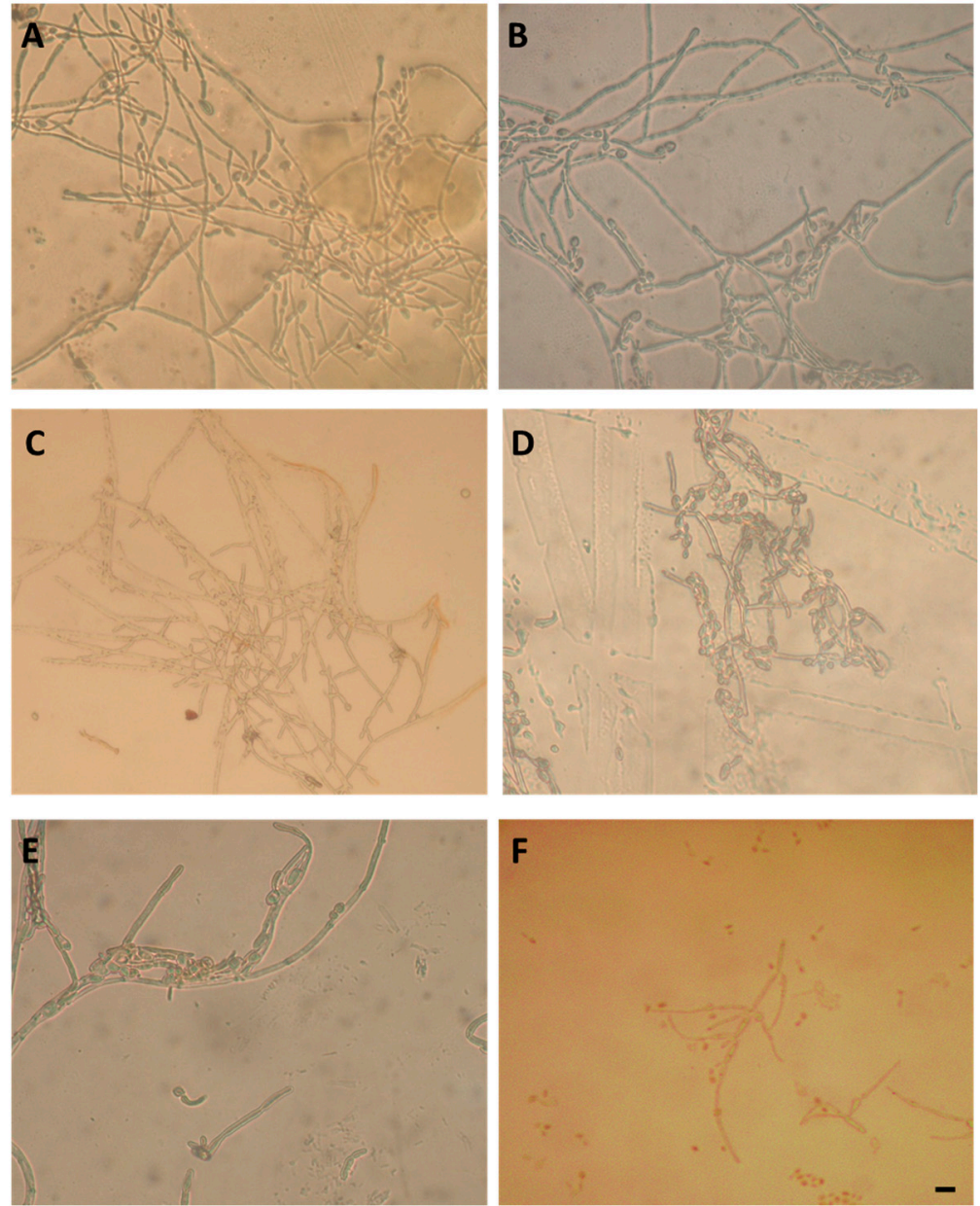

Figure 9. Inverted microscope images (400× magnification) of C. albicans SC5314 biofilms grown on different surfaces: (A) p(MSA-co-PTMSi5), (B) p(MSA-co-PTMSi1), (C) p(MPC-co-PTMSi5), (D) $\mathrm{p}$ (F6-co-PTMSi5), (E) p(F6-co-PTMSi1) and (F) glass (scale bar denotes $10 \mu \mathrm{m}$ for all images).

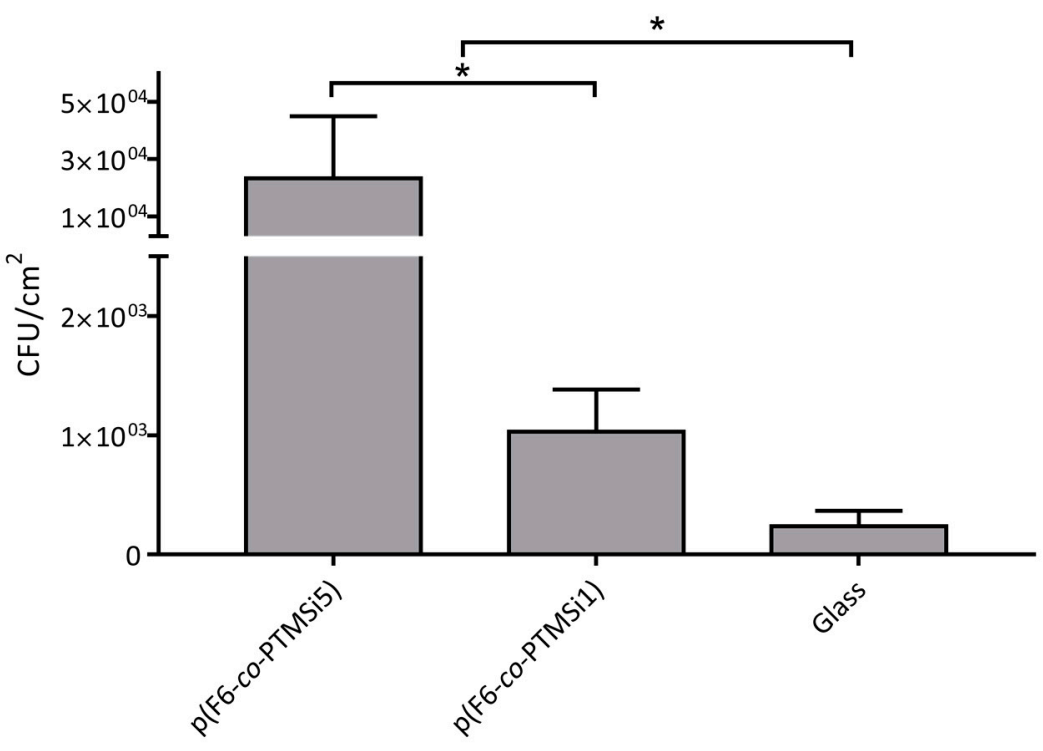

Figure 10. Adhesion of C. albicans to fluorinated films; * $p \leq 0.05$ (second set of experiments). 


\section{Conclusions}

Fluorinated (F6) and zwitterionic (MSA and MPC) copolymers containing low amounts of trimethoxysilyl groups were synthesized, and films therefrom were firmly anchored onto glass slides, for surface functionalization and chemical modification via a "grafting-to" reaction. AR-XPS measurements proved that the grafted polymer films were stable upon contact with water at least up to seven days of immersion, including the water-soluble copolymers p(MPC-co-PTMSix). It was also found that the film surface of fluorinated copolymers was largely populated by fluorinated moieties, both before and after immersion in water, consistent with their hydrophobic, low-surface-energy character. However, the film surface of zwitterionic copolymers was enriched in silicon, resulting in a more hydrophobic character than expected of their hydrophilic, high-surface-energy nature.

Biological assays against the most aggressive fungal pathogen $C$. albicans clearly pointed out that fluorinated copolymers were much more able to reduce the adhesion of $C$. albicans than the corresponding zwitterionic copolymers. The amount of F6 counits in the copolymer played a role in decreasing cell attachment, with the copolymer p(F6-co-PTMSi1) richer in fluorinated component being the best performer. Therefore, this work helps to overcome some of the discrepancies present in the literature about the role of zwitterionic and fluorinated polymers in preventing the adhesion of C. albicans and can provide initial guidelines for the synthesis of polymers with a tailored hydrophilic/hydrophobic balance to combat biofouling. The question of the contrasting "preferences" of biofouling agents to adhere and settle on surfaces is highly relevant in diverse fields of advanced applications. For one example, such fluorinated copolymers might be considered as surface modifiers of biomedical silicones, to be potentially employed in other-than-typical dental materials, to enhance resistance to $C$. albicans colonization.

Author Contributions: Conceptualization, F.D.F., A.T. and E.M. (Elisa Martinelli); methodology, E.M. (Elena Masotti), N.P. and E.G.; software, E.G., F.V. and A.B.; validation, A.T. and E.M. (Elisa Martinelli); formal analysis, G.G.; investigation, E.M. (Elena Masotti), I.F., A.G., F.V. and A.B.; resources, G.G., F.D.F. and E.M. (Elisa Martinelli); data curation, E.G. and E.M. (Elisa Martinelli); writing—original draft preparation, A.T. and E.M. (Elisa Martinelli); writing-review and editing, G.G.; visualization, E.G.; supervision, G.G.; project administration, E.M. (Elisa Martinelli); funding acquisition, G.G. All authors have read and agreed to the published version of the manuscript.

Funding: This research was funded by the University of Pisa (Progetti di Ricerca di Ateneo, PRA_2017_17).

Conflicts of Interest: The authors declare no conflicts of interest.

\section{References}

1. Bixler, G.D.; Bhushan, B. Biofouling: Lessons from nature. Philos. Trans. R. Soc. A Math. Phys. Eng. Sci. 2012, 370, 2381-2417. [CrossRef] [PubMed]

2. Galli, G.; Martinelli, E. Amphiphilic polymer platforms: Surface engineering of films for marine antibiofouling. Macromol. Rapid Commun. 2017, 38. [CrossRef] [PubMed]

3. Walker, J.; Surman, S.; Jass, J. Industrial Biofouling Detection, Prevention and Control; Wiley: New York, NY, USA, 2000.

4. Railkin, A.I. Marine Biofouling: Colonization Processes and Defenses; CRC Press: Boca Raton, FL, USA, 2004.

5. Hellio, C.; Yebra, D. Advances in Marine Antifouling Coatings and Technologies; Woodhead Publishing: Boca Raton, FL, USA, 2009.

6. Khatoon, Z.; McTiernan, C.D.; Suuronen, E.J.; Mah, T.F.; Alarcon, E.I. Bacterial biofilm formation on implantable devices and approaches to its treatment and prevention. Heliyon 2018, 4. [CrossRef] [PubMed]

7. Joo, H.S.; Otto, M. Molecular basis of in vivo biofilm formation by bacterial pathogens. Chem. Biol. 2012, 19, 1503-1513. [CrossRef] [PubMed]

8. Sadekuzzaman, M.; Yang, S.; Mizan, M.F.R.; Ha, S.D. Current and recent advanced strategies for combating biofilms. Compr. Rev. Food Sci. Food Saf. 2015, 14, 491-509. [CrossRef]

9. Wall, G.; Montelongo-Jauregui, D.; Vidal Bonifacio, B.; Lopez-Ribot, J.L.; Uppuluri, P. Candida albicans biofilm growth and dispersal: Contributions to pathogenesis. Curr. Opin. Microbiol. 2019, 52, 1-6. [CrossRef] 
10. Uppuluri, P.; Pierce, C.G.; Lopez-Ribot, J.L. Candida albicans biofilm formation and its clinical consequences. Future Microbiol. 2009, 4, 1235-1237. [CrossRef]

11. Song, F.; Koo, H.; Ren, D. Effects of material properties on bacterial adhesion and biofilm formation. J. Dent. Res. 2015, 94, 1027-1034. [CrossRef]

12. Martinelli, E.; Guazzelli, E.; Galli, G. Recent advances in designed non-toxic polysiloxane coatings to combat marine biofouling. In Marine Coatings and Membranes; Mittal, V., Ed.; Central West Publishing: Botanic Way, Australia, 2019; pp. 137-180. ISBN 978-1-925823-47-9.

13. Martinelli, E.; Pretti, C.; Oliva, M.; Glisenti, A.; Galli, G. Sol-gel polysiloxane films containing different surface-active trialkoxysilanes for the release of the marine foulant Ficopomatus enigmaticus. Polymer 2018, 145, 426-433. [CrossRef]

14. Wenning, B.M.; Martinelli, E.; Mieszkin, S.; Finlay, J.A.; Fischer, D.; Callow, J.A.; Callow, M.E.; Leonardi, A.K.; Ober, C.K.; Galli, G. Model amphiphilic block copolymers with tailored molecular weight and composition in PDMS-based films to limit soft biofouling. ACS Appl. Mater. Interfaces 2017, 9, 16505-16516. [CrossRef]

15. Oliva, M.; Martinelli, E.; Galli, G.; Pretti, C. PDMS-based films containing surface-active amphiphilic block copolymers to combat fouling from barnacles B. amphitrite and B. improvisus. Polymer 2017, 108, 476-482. [CrossRef]

16. Soll, D.R.; Daniels, K.J. Plasticity of Candida albicans biofilms. Microbiol. Mol. Biol. Rev. 2016, 80, 565-595. [CrossRef] [PubMed]

17. Seneviratne, C.J.; Jin, L.; Samaranayake, L.P. Biofilm lifestyle of Candida: A mini review. Oral Dis. 2008, 14, 582-590. [CrossRef] [PubMed]

18. Donlan, R.M. Biofilms: Microbial life on surfaces. Emerg. Infect. Dis. 2002, 8, 881-890. [CrossRef] [PubMed]

19. Silva-dias, A.; Miranda, I.M.; Branco, J.; Monteiro-soares, M.; Pina-vaz, C.; Rodrigues, A.G. Adhesion, biofilm formation, cell surface hydrophobicity, and antifungal planktonic susceptibility: Relationship among Candida spp. Front Microbiol. 2015, 6, 205. [CrossRef]

20. Oh, S.H.; Cheng, G.; Nuessen, J.A.; Jajko, R.; Yeater, K.M.; Zhao, X.; Pujol, C.; Soll, D.R.; Hoyer, L.L. Functional specificity of Candida albicans Als3p proteins and clade specificity of ALS3 alleles discriminated by the number of copies of the tandem repeat sequence in the central domain. Microbiology 2005, 151, 673-681. [CrossRef]

21. Kang, S.H.; Lee, H.J.; Hong, S.H.; Kim, K.H.; Kwon, T.Y. Influence of surface characteristics on the adhesion of Candida albicans to various denture lining materials. Acta Odontol. Scand. 2013, 71, 241-248. [CrossRef]

22. Lazarin, A.A.; Machado, A.L.; Zamperini, C.A.; Wady, A.F.; Spolidorio, D.M.P.; Vergani, C.E. Effect of experimental photopolymerized coatings on the hydrophobicity of a denture base acrylic resin and on Candida albicans adhesion. Arch. Oral Biol. 2013, 58, 1-9. [CrossRef]

23. Izumida, F.E.; Moffa, E.B.; Vergani, C.E.; Machado, A.L.; Jorge, J.H.; Giampaolo, E.T. In vitro evaluation of adherence of Candida albicans, Candida glabrata, and Streptococcus mutans to an acrylic resin modified by experimental coatings. Biofouling 2014, 30, 525-533. [CrossRef]

24. Hirasawa, M.; Tsutsumi-Arai, C.; Takakusaki, K.; Oya, T.; Fueki, K.; Wakabayashi, N. Superhydrophilic co-polymer coatings on denture surfaces reduce Candida albicans adhesion-An in vitro study. Arch. Oral Biol. 2018, 87, 143-150. [CrossRef]

25. Azuma, A.; Akiba, N.; Minakuchi, S. Hydrophilic surface modification of acrylic denture base material by silica coating and its influence on Candida albicans adherence. J. Med. Dent. Sci. 2012, 59, 1-7.

26. Zamperini, C.A.; Machado, A.L.; Vergani, C.E.; Pavarina, A.C.; Giampaolo, E.T.; da Cruz, N.C. Adherence in vitro of Candida albicans to plasma treated acrylic resin. Effect of plasma parameters, surface roughness and salivary pellicle. Arch. Oral Biol. 2010, 55, 763-770. [CrossRef] [PubMed]

27. Price, C.L.; Williams, D.W.; Waters, M.G.J.; Coulthwaite, L.; Verran, J.; Taylor, R.L.; Stickler, D.; Lewis, M.A.O. Reduced adherence of Candida to silane-treated silicone rubber. J. Biomed. Mater. Res. Part B Appl. Biomater. 2005, 74B, 481-487. [CrossRef] [PubMed]

28. Shirley, D.A. High-resolution x-ray photoemission spectrum of the valence bands of gold. Phys. Rev. B 1972, 5, 4709-4714. [CrossRef]

29. Moulder, J.F.; Chastain, J. Handbook of X-ray Photoelectron Spectroscopy: A Reference Book of Standard Spectra for Identification and Interpretation of XPS Data; Update; Physical Electronics Division, Perkin-Elmer Corp.: Eden Prairie, MN, USA, 1992; ISBN 0962702625. 
30. McIntyre, N.S.; Chan, T.C. Practical Surface Analysis 1; Briggs, D., Seah, M.P., Eds.; Wiley: Chichester, UK, 1990; p. 485.

31. Smoluchowski, M.V. Versuch einer mathematischen Theorie der Koagulationskinetik kolloider Lösungen. Z. Phys. Chem. 1918, 92U, 129-168. [CrossRef]

32. Brandrup, J.; Immergut, E.H.; Grulke, E.A. Polymer Handbook, 4th ed.; Wiley \& Sons, Inc.: New York, NY, USA, 1999; ISBN 0471166286.

33. Sorgi, C.; Martinelli, E.; Galli, G.; Pucci, A. Julolidine-labelled fluorinated block copolymers for the development of two-layer films with highly sensitive vapochromic response. Sci. China Chem. 2018, 61, 947-956. [CrossRef]

34. Durmaz, Y.Y.; Sahkulubey, E.L.; Yagci, Y.; Martinelli, E.; Galli, G. A novel poly(p-phenylene) containing alternating poly(perfluorooctylethyl acrylate-co-methyl methacrylate) and polystyrene grafts by combination of atom transfer radical polymerization and Suzuki coupling processes. J. Polym. Sci. Part A Polym. Chem. 2012, 50, 4911-4919. [CrossRef]

35. Galli, G.; Martinelli, E.; Chiellini, E.; Ober, C.K.; Glisenti, A. Low surface energy characteristics of mesophase-forming $\mathrm{ABC}$ and $\mathrm{ACB}$ triblock copolymers with fluorinated B blocks. Mol. Cryst. Liq. Cryst. 2005, 441, 211-226. [CrossRef]

36. Fukazawa, K.; Ishihara, K. Synthesis of photoreactive phospholipid polymers for use in versatile surface modification of various materials to obtain extreme wettability. ACS Appl. Mater. Interfaces 2013, 5, 6832-6836. [CrossRef]

37. Honda, T.; Nakao, A.; Ishihara, K.; Higaki, Y.; Higaki, K.; Takahara, A.; Iwasaki, Y.; Yusa, S. Polymer coating glass to improve the protein antifouling effect. Polym. J. 2018, 50, 381-388. [CrossRef]

38. Martinelli, E.; Galli, G.; Cwikel, D.; Marmur, A. Wettability and surface tension of amphiphilic polymer films: Time-dependent measurements of the most stable contact angle. Macromol. Chem. Phys. 2012, 213, 1448-1456. [CrossRef]

39. Dembele, F.; Tasso, M.; Trapiella-Alfonso, L.; Xu, X.; Hanafi, M.; Lequeux, N.; Pons, T. Zwitterionic silane copolymer for ultra-stable and bright biomolecular probes based on fluorescent quantum dot nanoclusters. ACS Appl. Mater. Interfaces 2017, 9, 18161-18169. [CrossRef]

40. Xu, Y.; Takai, M.; Ishihara, K. Protein adsorption and cell adhesion on cationic, neutral, and anionic 2-methacryloyloxyethyl phosphorylcholine copolymer surfaces. Biomaterials 2009, 30, 4930-4938. [CrossRef]

41. Guo, S.; Jańczewski, D.; Zhu, X.; Quintana, R.; He, T.; Neoh, K.G. Surface charge control for zwitterionic polymer brushes: Tailoring surface properties to antifouling applications. J. Colloid Interface Sci. 2015, 452, 43-53. [CrossRef] [PubMed]

42. Polzer, F.; Heigl, J.; Schneider, C.; Ballauff, M.; Borisov, O.V. Synthesis and analysis of zwitterionic spherical polyelectrolyte brushes in aqueous solution. Macromolecules 2011, 44, 1654-1660. [CrossRef] 